\title{
Identification of Durability Problems in Earth Buildings
}

\author{
K. P. Arandara and C. Jayasinghe
}

\begin{abstract}
Sri Lankan house construction in ancient times was dominated by earth construction. However in the past few decades, earth construction has been overtaken by burnt bricks and cement blocks in the housing industry. However, stabilized earth was reintroduced to Sri Lanka with the development of sustainable construction concepts and due to high cost of brick and block masonry construction.
\end{abstract}

The stabilized earth construction includes Compressed Stabilized Earth Blocks (CSEB) and rammed earth construction. In order to popularize these technologies, the strength and durability of such materials have to be comparable with the brickwork and cement block work.

A number of past studies conducted have determined the strength properties of both the stabilized earth masonry which have been proven as equally good as the conventional materials. In order to assess durability of earth buildings a detailed field study was conducted to investigate the problems associated with the existing earth structures. These field studies included ancient houses and recently built houses with stabilized and un-stabilized earth, with parameters like wall thickness, plinth level, wall spans and heights, etc. This study provides very useful information to quantify and access the levels of durability problems with different earth bricks, blocks and walls. This paper presents the outcome of a detailed study conducted by investigating the durability problems of existing earth buildings and also the testing methods to assess the durability of different earth walls. The outcome of this research will be very useful to improve the durability of earth buildings.

Keywords: Earth walls, Durability

\section{Introduction}

Earth is the oldest building material known, with recorded cases of the use of earth bricks dating back to Mesopotamia around 10, $000 \mathrm{BC}$. The oldest known existing earth building, the Pueblo at Taos in New Mexico, is 900 years old. The use of earth as a building material was revived in early 1970s in Australia following the energy crisis [1]. At present there is a growing market for earth wall buildings, with commercial building companies moving towards more durable materials of stabilized rammed earth and compressed stabilized earth bricks and blocks. Although the strength is proven to be adequate, there is some consumer resistance for earth building materials considering its durability properties. Therefore much work is needed to identify the magnitude and nature of durability problems and to develop different measures to enhance durability of earth building materials. There is still, however, some consumer resistance to these materials and much work is needed to convince the general public on durability aspects of earth buildings
However, with prevailing sand crisis and environmental problems associated with conventional construction methods, stabilized earth has been again introduced in Sri Lanka with some technological advancement. Recently, it has become architecturally desirable to leave earth walls as natural as possible without applying plasters and renderings and has given rise to questions as to long term resistance due to driving rain.

Therefore, a detailed study is required to investigate the durability problems of earth buildings. This paper covers a study to identify and quantify the durability problems. This also includes the scientific materials to access the durability of earth building materials.

This paper presents the durability problems of earth buildings and the suggestions to mitigate

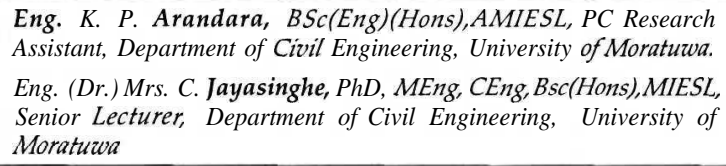


such problems with modern earth building construction methods. The field study includes houses built with rammed earth; mud Blocks, CSEB, interlocking Soil Blocks, Stabilized and Un-stabilized, Kabock and Rubble masonry bonded with clay etc.

\section{Objectives}

The main objectives are to identify the durability problems of the earth buildings in Sri Lanka and to propose mitigation methods to avoid such problems.

\section{Methodology}

In order to achieve the above objectives, the following methodology was adopted:

- A field study was conducted to investigate the durability problems of earth buildings.

- Results of the field study were analyzed and most common durability problems were identified

- Durability testing methods on earth buildings were devised for the Sri Lankan climatic conditions, to assess various mitigatory measures proposed.

\section{Field study}

A sample of 50 houses was covered in the filed study. This included houses built in different parts of the country such as; Matara, Gampaha, Polgahawela, Avissawella and upcountry; Hatton, Maskelliya and Kandy. Some of these houses were built using indigenous construction techniques with earth as the main walling material.

Houses inspected in Gampha (BiyagamaRanavirugama), the walls are out of rammed earth. Some of the houses were rendered with a cement plaster and then paints were applied on it (Figure 1). Those houses are about 15 years old.

Houses inspected in Matara are 20 to 35 years old and most of those were constructed with stabilized soil blocks. These houses were painted directly without applying a plastering. Few houses were applied with a cement plaster (Figure 2) and normal paints applied on it.

There were some houses which were built with un-stabilized soil blocks. Those are around 15 years old. There was another category of houses

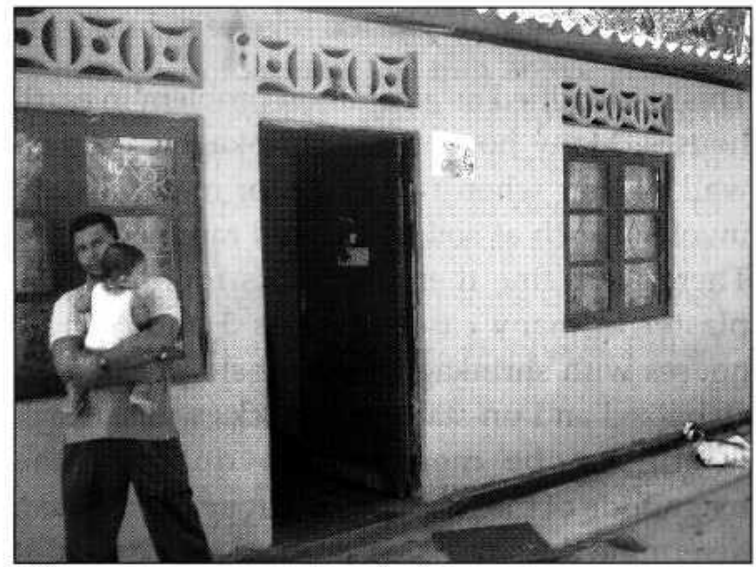

Figure 1: A rammed Earth house in Ranavirugama

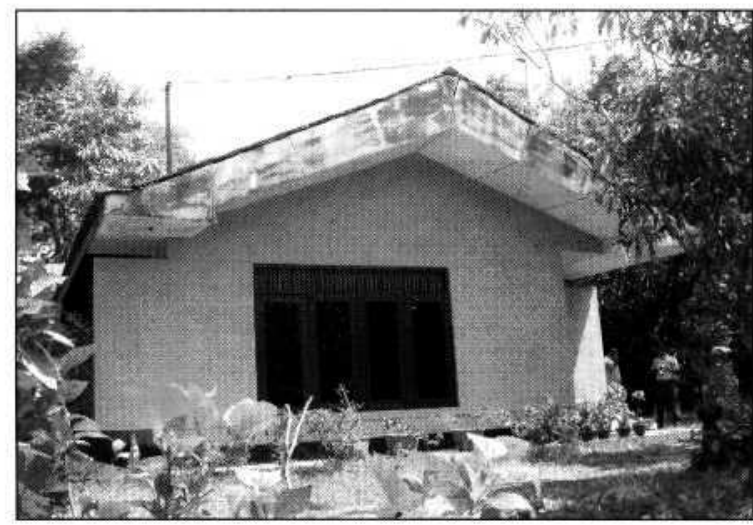

Figure 2: A house made out of Cement Stabilized soil blocks in Matara

included in the field study, which are over 75 years old, built with rubble and bonded with soil mortar. The sample of 50 houses consisted of $20 \%$ rammed earth, $59 \%$ stabilized soil blocks, $8 \%$ un-stabilized soil blocks and $13 \%$ rubble with soil mortar houses. Chart 1 shows the categories included in the sample.

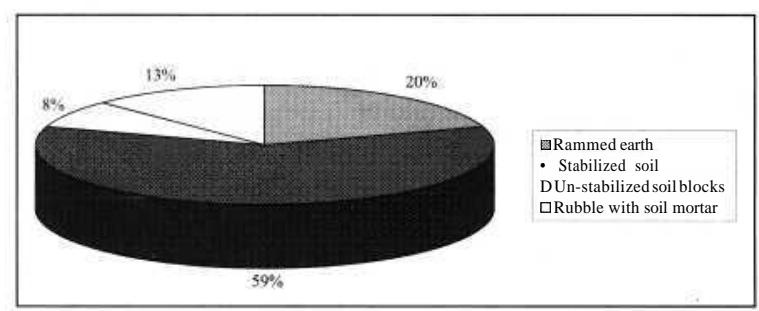

Chart 1: Percentages of walling materials used in the houses studied

\section{Durability problems identified}

Various durability problems were identified in earth buildings covered in the field study. Each category of problem is described in Sections 5.1 to 5.7 


\subsection{Cracks on wall plaster}

This is identified as a common problem in earth houses. Many houses had shrinkage cracks on wall plaster when two types of materials are involved such as soil blocks and rammed earth. There were fine thermal cracks found on the plaster in many cases. Figures 3 and 4 show houses with shrinkage cracks that appeared on stabilized and un-stabilized blocks walls. Crack width can be measured to quantify the magnitude of the problem. The type of crack can determine the associated problems such as; if it is a shrinkage crack, it is usually a through crack. In some instances it can be as wide as 2 to $3 \mathrm{~mm}$. Plaster cracks are generally occur on the wall surface which are not through cracks. Plaster cracks are usually very fine in width.

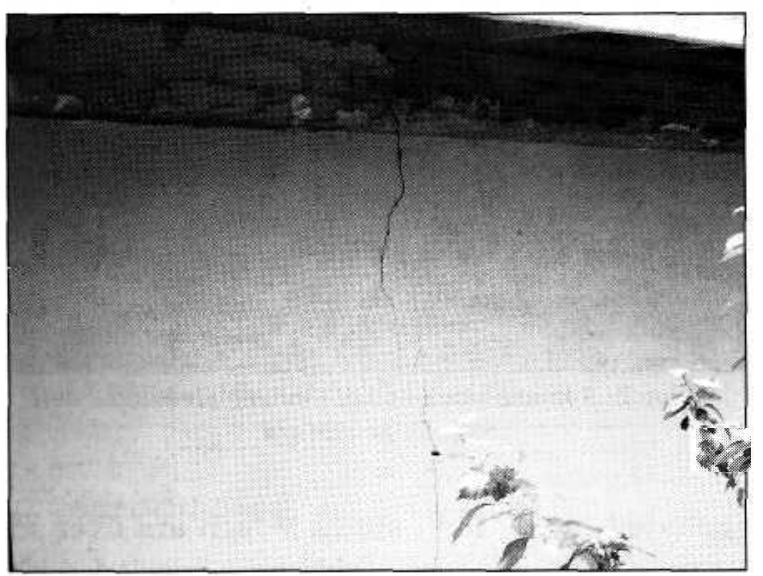

Figure 3: Shrinkage cracks of the walls of a house made out of cement Stabilized Soil Blocks in Matara

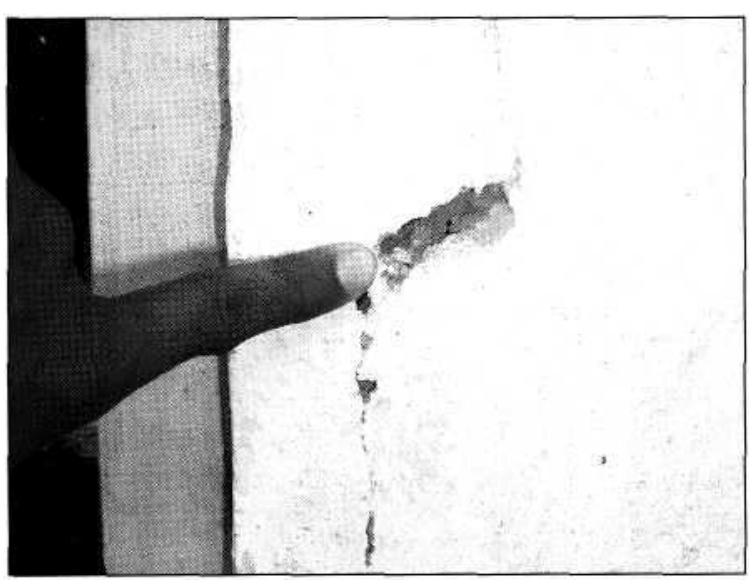

Figure 4: A thermal crack of the wall of a house made out ofun-stabilized soil blocks in Kosgama-Avissawella

\subsection{Water absorption}

Earth walls are more prone to deteriorate with high water absorption, if not stabilized properly. In a tropical country like Sri Lanka high rainfall can cause problems unless proper detailing is done to eliminate rain water splashing on walls.

If the earth walls get saturated; wet strength of the wall will govern the stability. This situation has been identified in some of the houses and an example is shown in Figure 5. Such houses have less eave length and low plinth level.

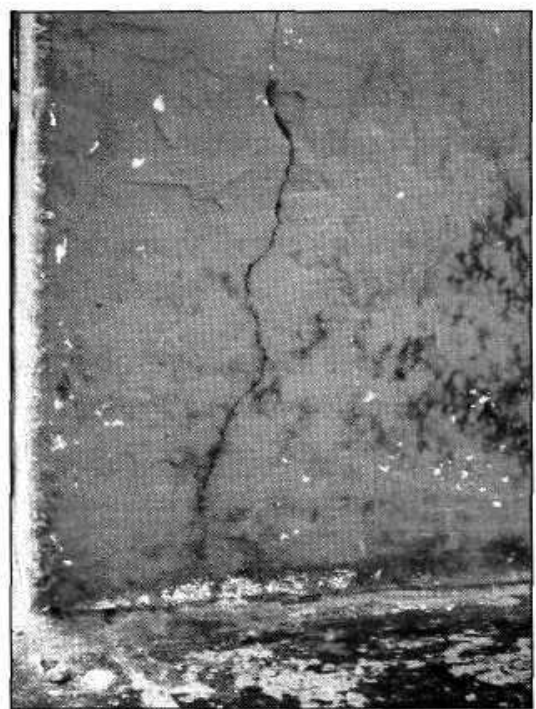

Figure 5: A wetted wall made out if stabilized soil block

In order to quantify the acceptable level of wet strength; the earth building units must have at least $0.4 \mathrm{x}$ dry strength [2]

\subsection{Erosion of walls due to driving rain}

Some houses inspected during the filed survey were subjected to erosion due to driving rain. Figure 6 shows a picture of such a house. Most of the un-stabilized earth walls were subjected to this problem. If the wall is not plastered; the erosion can get aggravated. In case of this, erosion depth and eroded area could be measured so as to get a better view of behavior of walls due to driving rain. To measure the erosion depth, a flat ended rod of $10 \mathrm{~mm}$ diameter can be used since it has been specified for spray test which is described in section 6.1 of this paper.

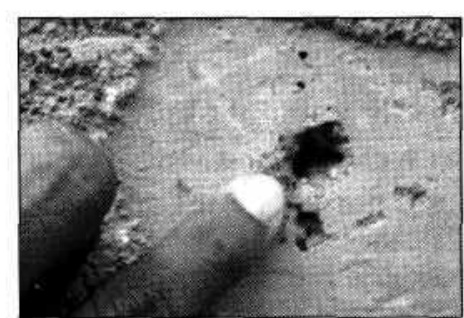

Figure 6: A defect on an un-stabilized soil block wall of a house in Kosgama-Avissazella 


\subsection{Separation of wall plaster}

This problem was identified in some of the houses. An example is shown in Figure 7. This could be due to incompatibility of plaster and walling material not properly bonded to the wall. Small portion of plaster separated from the wall could be observed at several places. This may lead to further deterioration of wall since the protective layer is no longer available to safeguard the wall from adverse weathering elements. In order to quantify this durability problem, area of separated plaster and the depth of deterioration can be used. The guidelines with acceptable levels of deterioration will be determined which contains solutions to durability problems.

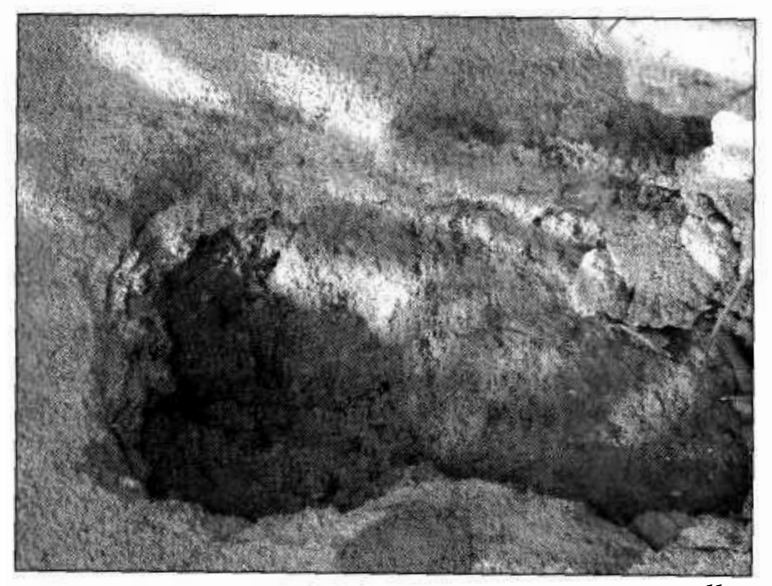

Figure 7: Separation ofthe plaster from a earth wall

\subsection{Inadequate plinth level}

This was identified as another drawback in some of the earth houses which contributed to scouring and erosion (Figure 8). There were few houses with a very low plinth level (DPC level) and adequate (around $450 \mathrm{~mm}$ ) plinth levels also

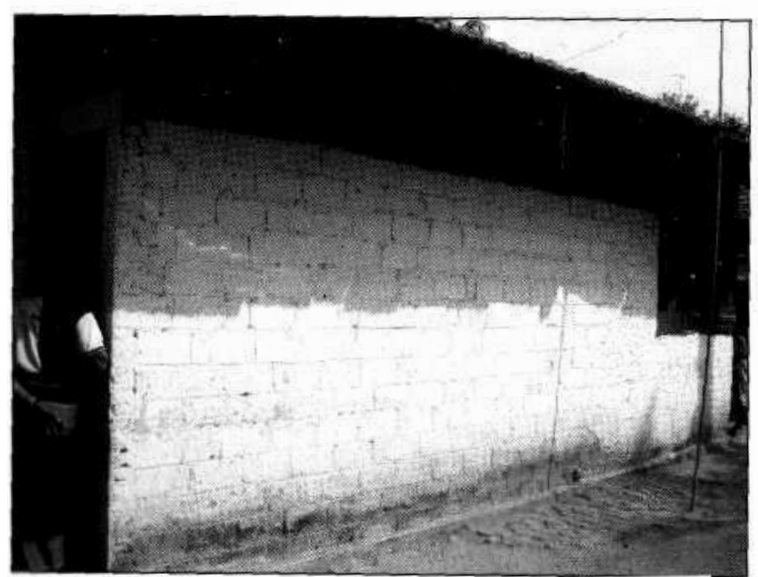

Figure 8: A house made out of stabilized soil blocks with inadequateplinth level were found in several ancient houses. Generally, a plinth level of around $150 \mathrm{~mm}$ above ground is recommended [3]. Walls of houses with shallow plinth level had high erosion depth which was more than $10 \mathrm{~mm}$ in depth due to driving rainfall unlike the ancient houses with high plinth levels. Chart 2 presents the number of houses with and without adequate plinth level.

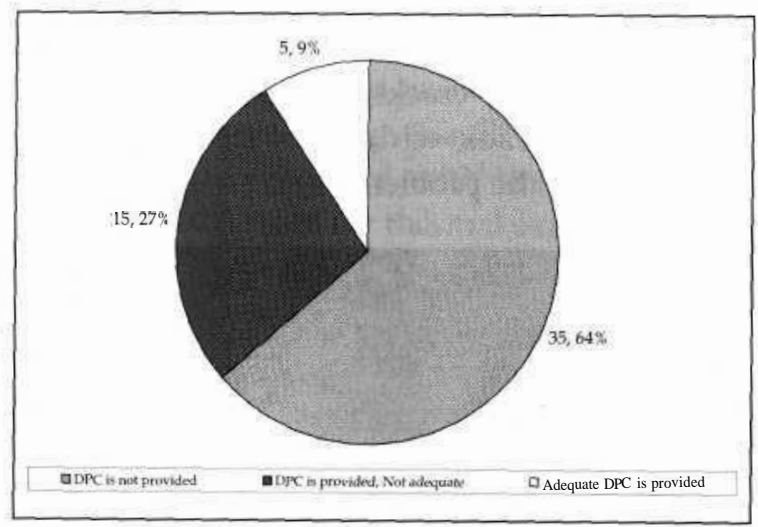

Chart 2: The percentage of house with and without adequate plinth level (DPC)

\subsection{Termite and insects attack}

Especially the un-stabilized earth walls had faced this problem. When a wall gets wet during rainy seasons it creates a conducive environment for the insects to survive in the walls. Mainly the unstabilized earth houses had termite problem and the number of houses identified with this problem is $28 \%$ of the sample considered in the field study. This problem may not arise with stabilized earth.

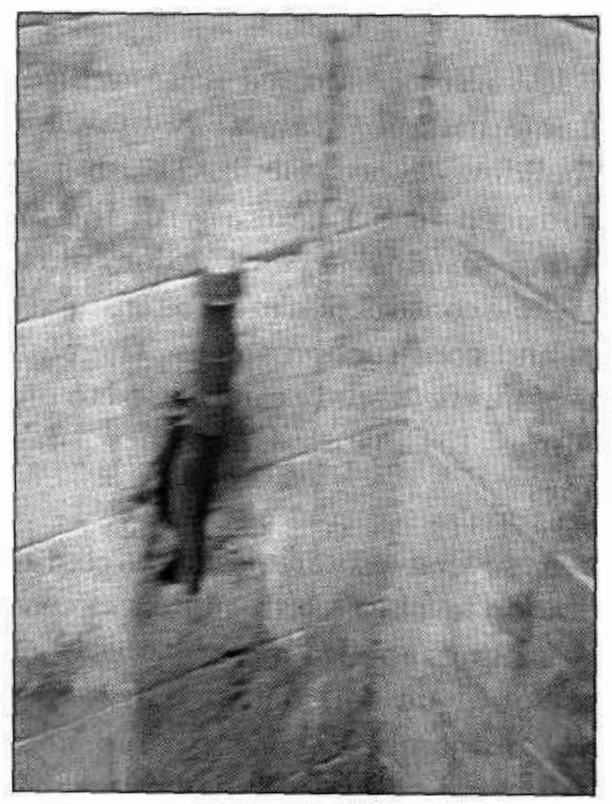

Figure 9: The problems with water lines 


\subsection{Cracks forming at $T$ and $L$ junctions}

This defect was mainly identified in rammed earth houses where two different materials were used in wall and at the junction columns. Deferential shrinkage properties of different materials can initiate this problem of durability [4]. Figure 10 shows an example of this nature. There were about $20 \%$ houses which had this problem. The nature of the crack can be determined us to whether it is a through crack or not. Shrinkage cracks are generally through cracks. The crack width can determine the magnitude of the problem.

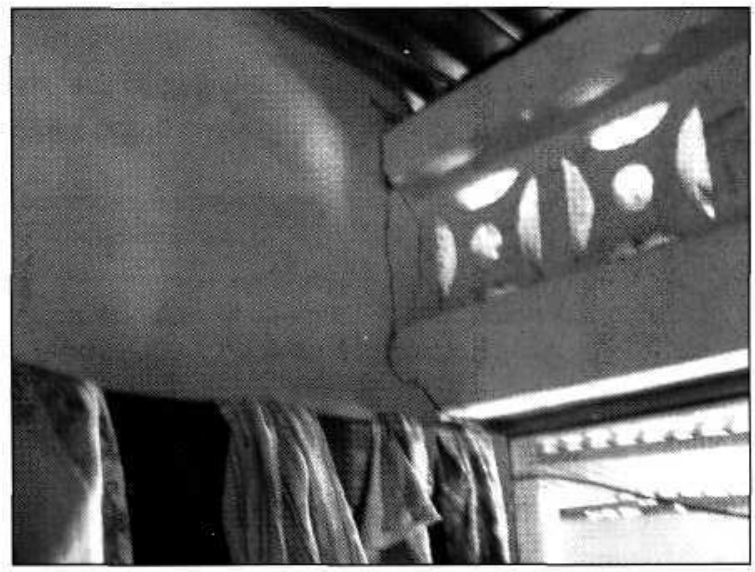

Figure 10: Comer cracks in Rammed earth walls

As a solution materials which are compatible with each other can be used in the wall and in junction columns (L and T shape).

\section{Experiments to determine durability aspects}

The field survey conducted had revealed very useful information; on durability problems of earth buildings. Since stabilized earth has been reintroduced to Sri Lanka with the aim of promoting sustainable construction, durability of the whole construction must be ensured at the design and construction stages. Therefore the results of this field study can be used to propose guidelines to ensure durability of earth buildings.

However, several tests are needed to confirm the stabilization levels of earth and effectiveness of surface coatings applied on earth walls. Some of those would be soil based paints applied directly on compressed earth blocks or on rammed earth, soil based renderings or some commercially available paints.
Earth construction has now been improved and adopted with different architectural designs. Hence wide variations of surface coatings are applied to obtain a pleasing finish. In order to ensure the durability of earth buildings, the levels of stabilization required and the success rate of finishing coats, the following tests can be carried out:

There are durability tests specified in various earth building standards and codes of practices.

\subsection{Accelerated erosion test}

This test is used to determine relative erosion resistance of earth blocks. Specimens are subjected to a continuous jet of water spray for 60 minutes or until water has completely penetrated the specimen. Performance, in terms of erosion rate (mm/hour), is determined on the basis of pitting depth or time taken to completely penetrate the specimen. The apparatus required for the test is shown in Figure 11. It includes a stand mounted $50 \mathrm{~mm}$ spray, water pump, pipes and valves, pressure gauge, water source, filtration screen to remove particulate matter, mounting specimen, shield and gasket. This apparatus is being manufactured at University of Moratuwa, with the financial support from GTZ, Germany.

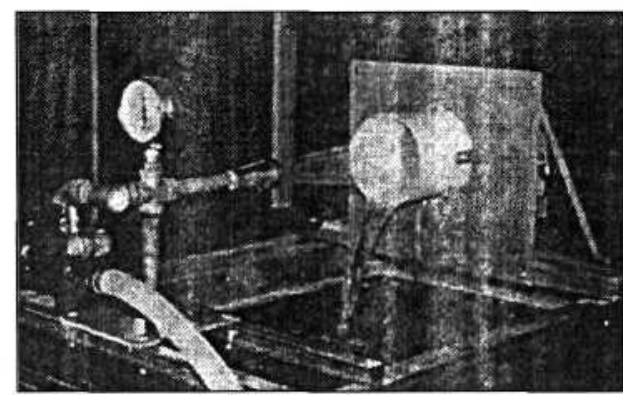

figure 11: Erosion test apparatus

(As a reference Australian earth building hand book, Assessed by Queensland University of Technology on 19 April 2005)

\subsection{Wetting and drying test}

A cyclic wet - dry test designed to eliminate generally unacceptable mixes, especially those containing reactive clays. Such test may be undertaken on one or more specimens from an agreed lot. For rammed earth and poured earth testing, $a$ representative block $\left(300_{-} 300_{-} 125\right.$ $\mathrm{mm}$ thick) should be prepared. All test specimens should be cured for 28 days before testing. The specimen is placed face down in 10 $\mathrm{mm}$ of sufficient water for 30 seconds. After that 
the specimen is dried until there is no colour change. This cycle of water immersion and drying has to be continued for a total of six times, immersing the same face each time [4]. The requirements of this test are met if after drying none of the following conditions are observed in the specimen:

- Surface cracking patterns

- Local swelling

- $\quad$ Pitting

- $\quad$ Loss of soil layers etc;

\subsection{Wet strength of soil blocks}

The specimen of soil blocks or rammed earth also subjected to compressive strength testing after being immersed in water for 24 hours. This will gives the wet compressive strength of earth block or specimen. This would represent the adverse condition of fall saturation of blocks in a flood situation. If the wet strength is above 0.4 $\mathrm{x}$ dry strength, the brick or blocks are acceptable for this condition [2].

\subsection{Shrinkage box test}

This test requires a timber or metal mould with internal dimensions of $40 \mathrm{~mm}$ (wide) x $40 \mathrm{~mm}$ (high) x $60 \mathrm{~mm}$ (long) as shown in Figure 12. First, the soil sample should be sieved with a $5 \mathrm{~mm}$ sieve. Then $2.0 \mathrm{~kg}$ to $2.5 \mathrm{~kg}$ sample of the soil is mixed with sufficient water close to its optimum moisture content. Then, the mould is filled completely with firm wet soil; periodic tapping of the mould helps to remove trapped air. After levelling off the top total length the sample in the mould is sun dried for 7 to 14 days, until all shrinkage occurs. The total length of dried soil is measured to the nearest millimetre and then the percentage linear

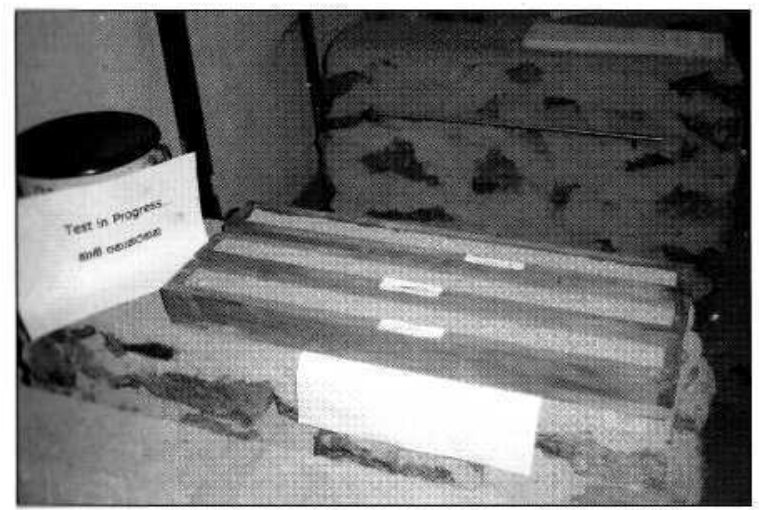

Figure 12: Shrinkage test mouldfilled with soil shrinkage is calculated. According to the percentages, the soil can be tested on the suitability for block manufacturing or rammed earth and as to whether the cement percentages are adequate for stabilization.

\subsection{Shrinkage on wall panels}

Shrinkage test is used to determine soil suitability and amount of cement required for stabilized earth constructions [5]. In the experiment, a steel rod is fixed to the test wall panel with a dial gauge (Figure 13). Dial gauge readings are recorded with the temperature readings to account for thermal expansion of the rod for few weeks. By using those readings, shrinkage pattern is identified and could make the comments on the soil used for the wall panel.

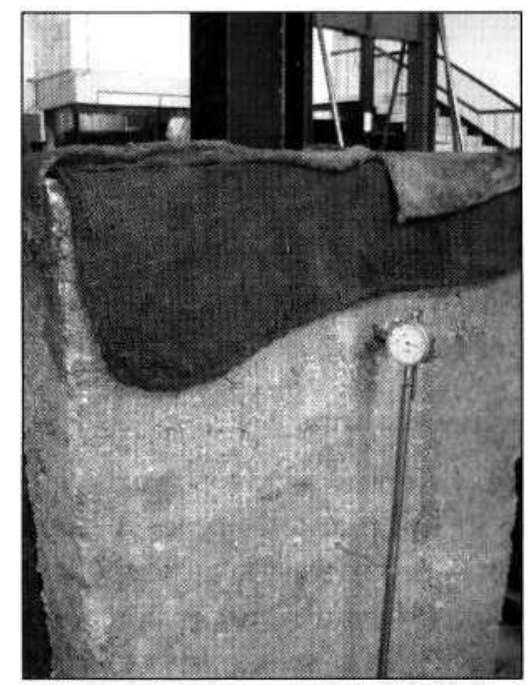

Figure 13: Shrinkage test on a rammed earth wall panel

\section{Proposed measures to improve durability of earth buildings}

Based on the problems identified in the field study, following measures are proposed to improve the durability of earth buildings:

\section{a) Long eaves}

Extension of eaves provides excellent protection for external walls from wind driven rainfall (Figure 14). As roofs must be adequately tied down against wind uplift forces, eaves extension in high - wind area will be limited unless additional anchorage can be provided [2].

\section{b) Higher plinth levels}

Plinth level (Level of DPC) should be placed at least $150 \mathrm{~mm}$ above ground level, and form 


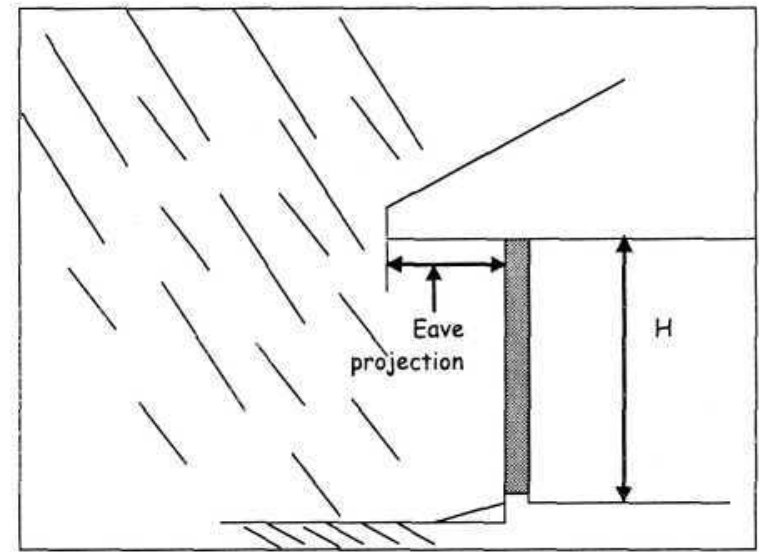

Figure 14: Protection from eaves projection

continuous protection with damp proofing on top surface of the plinth.

\section{c) Stabilization levels}

Stabilisation is the improvement of soil to make it more suitable for construction. Clay and sill content must be limited to $35 \%$ to ensure adequate durability and dimensional stability. For earth buildings, plasticity tests will give [9] sufficient indication of the stabilisation [6] [7]. Higher stabilization levels should be used for different materials used in rammed earth walls and corner columns.

\section{d) Protective coatings}

There are different kinds of surface coatings available in the market. Some of them are oil based paints, proprietary water repellents (PVA) or silicon based emulsions, water based paints and white wash. The suitability of such coatings is being checked with laboratory tests after while it will be possible to recommend some protective coatings for the Sri Lankan soils. The results will be published in another publication.

\section{e) Termite protection system}

Several measures are available to prevent termite damages. All major food sources (wood debris) can be removed from the vicinity of the building. Also, naturally resistant or preservative treated timbers can be used for all primary building elements to protect the building from termite attack [8]. Termite problems will not arise with stabilized soil (cementstabilized).

\section{Conclusions}

The field study conducted to identify durability problems of earth buildings revealed very useful information. The outcome of the study can be used to prepare detail guidelines on design and construction of earth buildings. This study has also identified the durability testing which could be carried out before recommending Compressed Stabilized Earth Block or stabilised rammed earth for any construction. In future, different earth masonry units will be subjected to above mentioned experiments on durability aspects to assess their stabilization levels and protective coatings.

The durability improvements suggested in this study such as; provision of long eaves, adequate stabilization levels, suitable protective coatings and minimizing shrinkage can be applied in the design and construction stages. Such measures will certainly ensure more durable structures built with stabilized earth as a walling material.

However, areas subjected to flooding needs special care in terms of durability. Therefore, special designs should be introduced for the houses built in such locations.

\section{Acknowledgement}

The authors wish to express their sincere thanks to NSF for providing financial support for this study. In addition to that we would thank to all those who arranged permission to visit all the houses covered in the field survey. Our special thanks are due for Mr. Printhy De Silva, Managing Director, Gado Lanka System Bricks (Pvt) Ltd and Mr. Dammika, an officer of the above company for the contribution given to make the field visits a success. The great support given by Mr. Fred Kumarapperuma for his guidance is highly appreciated. 


\section{References}

1. Heathcote K. A., "Durability of Earth Buildings", University of Technology, Sydney, 1995.

2. Australian Earth Building hand book, Assessed by Queensland University of Technology on 19 April 2005

3. Alferd B. Ngowi, "Improving the traditional earth construction: a case study of Bostuwana", Department of Civil engineering, University of Bostuwana, 1997.

4. ASTM Standard D 559-44.

5. Taylor P., Luther M.B., "Evaluating rammed earth walls: a case study, Deakin University and La Trobe University, Australia, 2003

6. Bahar R., Benzzoug M, Kenai S., "Performance of compacted cement - stabilized soil", University of Tizi - Ouzou and University of Bilada, Algeria, 2004

7. Venkatarama Reddy B. V., Lokras S. S., "Steam cured stabilized soil blocks for masonry construction", Energy and buildings, vol. 29, No. 29 - 33, March 1998.

8. Raymond N. Yong, Vahid R. Ouhadi, “ Experimental study on instability of bases on natural and lime / cement - stabilized clayey soils", North Saanich, B. C. , Canada, Bu - Ali Sian University, Iran, 2006.

9. Perera A., Jayasinghe C., "Strength characteristics and structural design methods fro compressed earth block walls", Masonry International, the British masonry society, United Kingdom, January, 2003. 